\title{
THREE NEW SYNONYMS AMONG CHINESE CAMAENID SNAILS (GASTROPODA: EUPULMONATA: CAMAENIDAE)
}

\author{
GUOYI ZHANG
}

Shandong Normal University, No. 88 East Wenhua Road, 250014 Jinan, China
(e-mail: starsareintherose@163.com); 단 https://orcid.org/0000-0002-3426-9273

ABSTRACT: Three new synonyms are recognised among recently described camaenid taxa from China. Two subspecies of the newly described Bradybaena changchunensis Sun, Zeng et He, 2017 are to be referred to B. virgo (Pilsbry, 1927), and the newly described Nesiohelix meiqiui Ge et He, 2017 is referred to Aegistohadra delavayana (Heude, 1885). Differences in the method of whorl counting are a major cause of this confusion. A further confusion over B. virgo was also revealed by this study.

KEY WORDS: synonymy, taxonomy, Camaenidae, China, land snail

\section{INTRODUCTION}

Three recent papers concerning terrestrial snails in China (HE \& ZHOU 2017, GE \& HE 2017, SUN et al. 2017), described six new species and subspecies on the basis of shell morphology. In particular, determinations were based mainly on whorl counts, but the method used by the authors (GE \& HE 2017, SUN et al. 2017) differed from that commonly accepted (KERNEY \& CAMERON 1979). A reassessment of the material shows that three of the new taxa are synonyms. Further, this reassessment corrects earlier misidentification of Bradybaena virgo (Pilsbry, 1927) and elucidates a synonym of $B$. similaris (Férussac, 1822).

\section{TAXONOMIC PART}

Class: Gastropoda

Subclass: Heterobranchia

Superfamily: Helicoidea Rafinesque, 1815

Family: Camaenidae Pilsbry, 1895

Genus: Bradybaena Beck, 1837

\section{Bradybaena virgo (Pilsbry, 1927)}

Ganesella virgo Pilsbry, 1927: 461-462, pl. 35, figs 7, $7 \mathrm{a}$.

Eulota murensis Cockerell, 1926: 227.
Fruticicola virgo - KURODA (1941: 27-28).

Bradybaena (Virginihelix) virgo - KURODA \& HABE (1949: 64, fig. 30); HABE (1956: fig. 1).

Ganesella arcasiana (Crosse et Debeaux, 1863) - CHEN \& GAO (1987: 108, fig. 138) (misidentification).

Ganesella virgo - CHEN \& GAO (1987: 109, fig. 139).

Karaftohelix arcasiana - KANTOR et al. (2009: 231); SYSOEV \& SCHILEYKO (2009: 180, fig. 101D) (misidentification).

Bradybaena virgo virgo (Pilsbry, 1927) - WANG et al. (2014: 10, figs 2D, 4D). 
Bradybaena virgo mongolia Wang et Zhou, 2014 WANG et al. (2014: 12, figs 2E, 4E).

Bradybaena changchunensis changchunensis Sun, Zeng et He, 2017: 23, fig. 1, new synonym

Bradybaena changchunensis harbinensis Sun, Zeng et He, 2017: 23, fig. 2, new synonym

Material examined. Photos of comparative material were used for comparison. They were obtained from the Academy of Natural Sciences of Philadelphia, Philadelphia, USA (ANSP) 99965, holotype, Ganesella virgo, 10 March, 1910, Wichu (or Uiju); the State Key Laboratory of Molluscan Quarantine and Identification, Fujian Entry-Exit Inspection \& Quarantine Bureau, Fuzhou, China (FJIQBC) 18466, holotype, Bradybaena virgo mongolia, 5 October, 1982, Zhalaiteqi, Inner Mongolia; the Zhejiang Museum of Natural History, Hangzhou, China (ZMNH) AIMS 27098, holotype, Bradybaena changchunensis changchunensis, Changchun, Jinlin; ZMNH AIMS 27099, holotype, Bradybaena changchunensis harbinensis, Harbin, Heilongjiang.

Remarks. The greatest notional difference between $B$. virgo and B. changchunensis is the number of whorls (SUN et al. 2017); B. changchunensis has six rather than seven whorls when a count is made using the standard method, based on the images in the original description. The specimens thus appear identical to those of $B$. virgo. The distributions of $B$. virgo and $B$. changchunensis are adjacent. PILSBRY (1927) described B. virgo from Uiju near Liaoning Province, and SUN et al. (2017) found B. changchunensis in Changchun, Jilin and Harbin, Heilongjiang. SuN et al. (2017) claimed that the new species could be clearly distinguished by the colour and pattern. The colour they described was white, almost transparent. B. changchunensis changchunensis had no colour pattern. PILSBRY (1927) described the colour of Ganesella virgo using the word "This species has a somewhat bullet-like contour and the pale colour of the Japanese species." SUN et al. (2017) did not consider papers by PILSBRY (1927) and WANG et al. (2014).

The holotype of G. virgo shows no bands. The distinguishing feature of Bradybaena changchunensis changchunensis and $B$. changchunensis harbinensis is the presence or absense of bands (SUN et al. 2017). Several surveys show that the presence or absence of bands among camaenids in general and in Bradybaena in particular is a variable character (KOMAI \& EMURA 1955, ASAMI et al. 1993) and cannot be treated as a diagnostic feature. In the absence of any anatomical and/or molecular studies, B. changchunensis and its subspecies should be treated as synonyms of $B$. virgo. SYSOEV \& SCHILEYKO (2009) and KANTOR et al. (2009) reporting B. virgo from Shanghai in south China misidentified it as Helix arcasiana Crosse et
Debeaux, 1863 which in fact is B. similaris (Férussac, 1822) (MARTENS 1867). There is nothing to suggest that B. virgo occurs in Shanghai or more to the south in China (COCKerell 1926, Pilsbry 1927, CHEN \& GAO 1987, KANTOR et al. 2009, SYSOEV \& SCHILEYKO 2009, Sun et al. 2009). Though the original figure of $H$. arcasiana is similar to $B$. virgo, the description of $H$. arcasiana does not match the picture. CROSSE \& DEBEAUX (1863) wrote "Diam. maj. 16, min. 14. Alt. 10 1/2 millim.". The shape is not globular; H. arcasiana is flatter. Compared to $H$. arcasiana, the whorls of $B$. virgo increase more rapidly. COCKERELL (1926) compared Eulota murensis, a synonym of $B$. virgo, with E. similaris var. arcasiana to make sure his species was new.

\section{Genus: Aegistohadra Wu, 2004}

\section{Aegistohadra delavayana (Heude, 1885)}

Nanina delavayana Heude, 1885: 103, pl. 26, fig. 9. Aegistohadra delavayana - WU (2004: 112-119, figs 28-32).

Nesiohelix meiqiui Ge et He, 2017: 14-16, figs 6-7, new synonym

Material examined. Institute of Zoology, Chinese Academy of Sciences, Beijing, China (IZCAS)type-2902-1 and IZCAS-type-2902-2, paratype, Nanina delavayana, Fa Kouan Tchen (Dali, Yunnan); ZMNH AIMS 27102, holotype, Nesiohelix meiqiui, Kunming, Yunnan (photos).

Remarks. A thorough comparison of the descriptions and figures shows that the whorl number of Nesiohelix meiqiui is ca. 5.75 instead of 6-7 reported by GE \& HE (2017), and their shells are identical. GE \& HE (2017) did not cite the papers by HEUDE (1885) and WU (2004).

GE \& HE (2017) collected specimens from Kunming, Yunnan. HEUDE (1885) used specimens from Ta-li fou (Dali, Yunnan, $25^{\circ} 40^{\prime} \mathrm{N}, 100^{\circ} 09^{\prime} \mathrm{E}$ ) (JOHNSON 1973). The distribution is almost the same. There is no evidence that Nesiohelix meiqiui is a new species.

\section{ACKNOWLEDGEMENTS}

I am indebted to The Biodiversity Heritage Library (www.biodiversitylibrary.org) and Google Books (https://books.google.com) for the access to literature. Thanks go to the online database (http:// clade.ansp.org/malacology/collections) provided by the Academy of Natural Sciences of Philadelphia. I am also grateful to my alma mater, the Zaozhuang Experimental School, for her tolerance for different opinions. 


\section{REFERENCES}

ASAMI T., FUKUDA H., TOMIYAMA K. 1993. The inheritance of shell banding in the land snail Bradybaena pellucida. Venus (Japanese Journal of Malacology) 52: 155-159. https://doi.org/10.18941/venusjjm.52.2_155

CHEN D-N., GAO J-X. 1987. Economic Fauna Sinica of China Terrestria Mollusca. Science Press, Beijing.

COCKERELLT.D.A. 1926. Somehelicoid snails from Manchuria. Annals and Magazine of Natural History, Series 9, 17: 98, 226-228. https://doi.org/10.1080/00222932608633396

Crosse H., Debeaux O. 1863. Diagnoses d'espèces nouvelles. Journal de Conchyliologie 11: 386. https://www. biodiversitylibrary.org/page/15338127\#page/392/ mode/1up

GE L., HE J. 2017. Description of two terrestrial gastropod species from Yunnan Province, China. Shell Discoveries 2: $14-15$.

HABE T. 1956. Notes on four Korean land snails. Doubutsugaku Zasshi 65: 191-193.

HE J., ZHOU Q. 2017. Records of Amphidromus from South China. Shell Discoveries 2: 3-6.

HEUDE P. M. 1885. Notes sur les mollusques terrestres de la Vallée du Fleuve Bleu. Mémoires concernant l'histoire naturelle de l'Empire chinois. De la Mission catholique, Chang-Hai. https://www.biodiversitylibrary. org/item/106316

JOHNSON R. I. 1973. Heude's molluscan types: or, Asian land and fresh water mollusks, mostly from the People's Republic of China, described by P. M. Heude. Department of Mollusks, Museum of Comparative Zoology, Harvard University, Cambridge, Massachusetts. https://www. biodiversitylibrary.org/item/25355

Kantor Y. I., Vinarski M. V., Schileyko A. A., Sysoev A. V. 2009. Catalogue of the continental mollusks of Russia and adjacent territories. Version 2.3.1, Available on line at https://www.ruthenica.com/documents/ Continental_Russian_molluscs_ver2-3-1.pdf (accessed 28 September 2018)

Kerney M. P., CAMERON R. A. D. 1979. A field guide to the land snails of Britain and North-West Europe. William Collins Sons \& Co. Ltd, London.
KOMAI T., EMURA S. 1955. A study of population genetics on the polymorphic land snail Bradybaena similaris. Evolution 9: 400-418. https://doi.org/10.1111/j.1558-5646.1955. tb01550.x

KurodA T., HABE T. 1949. Helicacea. Osaka, Japan.

KURODA T. 1941. Fruticicola virgo (Pilsbry) occurs widely in Manchoukuo. The Venus 11:27-28. https://www.jstage. jst.go.jp/article/venusomsj/11/1/11_KJ00004338281/ pdf

MARTENS E. VON 1867. Die preussische Expedition nach Ost-Asien. Nach amtlichen Quellen. Zoologischer Teil. Zweiter Band. Die Lanschnecken. Verlag der Königlichen Gehaimen Ober-Hofbuchcruckerei (R. v. Decker), Berlin. https://www.biodiversitylibrary.org/ item/49587

PILSBRY H. A. 1927. Review of the land Mollusca of Korea. Proceedings of the Academy of Natural Sciences of Philadelphia 78: 453-475 (1926). https://www.jstor. org/stable/4063959

SUN X., ZENG Z., HE J. 2017. Description of two new species of land snails (Bradybaenidae) from China. Shell Discoveries 2: 23-24.

SysOeV A., SCHILEYKO A. 2009. Land snails of Russia and adjacent countries. Pensoft Publishers, Sofia.

WANG P., XiaO Q., ZHOU W.-C., HWANG C.-C. 2014. Revision of three camaenid and one bradybaenid species (Gastropoda, Stylommatophora) from China based on morphological and molecular data, with description of a new bradybaenid subspecies from Inner Mongolia, China. ZooKeys 372: 1-16. https://doi.org/10.3897/ zookeys.372.6581

WU M. 2004. Preliminary phylogenetic study of Bradybaenidae (Gastropoda: Stylommatophora: Helicoidea). Malacologia 46: 79-125.

Received: January 15th, 2019

Revised: February 11th, 2019

Accepted: February 28th, 2019

Published on-line: March 19th, 2019 